\title{
The Management of Individual and Group Adaptation of Speedskaters to Training Loads Based on Biochemical Monitoring of Blood Parameters
}

\author{
Martynenko I.V. \\ Russian State University of Physical Education, Sport, \\ Youth and Tourism (State Central Order of Lenin Institute \\ of Physical Education) \\ Moscow, Russia \\ w0102w@ya.ru
}

\author{
Borisenkova E.S. \\ Ural State University of Physical Education \\ Chelyabinsk, Russia, \\ ekboris24@mail.ru
}

\begin{abstract}
The article presents the results of the study concerning the adaptation of a speedskater's body to intense physical exertion during certain intervals of a one-year macrocycle. The study involved athletes belonging to the "youth" age category (14-15 years old), training at all distances of allround events $(500 \mathrm{~m}, 1000 \mathrm{~m}, 1500 \mathrm{~m}, 3000 \mathrm{~m})$, as well as male sprinters and male all-rounders of 20-26 years old specializing in running short $(500 \mathrm{~m}, 1000 \mathrm{~m})$ and long distances $(1500 \mathrm{~m}, 3000$ $\mathrm{m}$ and $5000 \mathrm{~m}$ ) respectively. The article shows that the analysis of certain biochemical blood parameters, in particular hormones and metabolites, in the presence of hyperkinetic stress during the training activity of sprinters and all-rounders at the general preparatory stage, allows minimizing negative consequences in the form of fatigue. The article indicates that the competent management of maladaptive processes in speed skating at the beginning of a one-year macrocycle determines a qualitative increase in sports results in the future.
\end{abstract}

Keywords—speed skating; adaptation; general preparatory stage; one-year macrocycle; hormones; metabolites.

\section{INTRODUCTION}

Speed skating needs new research on improving the performance and performance of athletes in tournaments. Therefore, mainly this study is devoted to the formation of athletes adaptation with huge physical exertion.

It is well known that when studying the issues of individual and group adaptation of athletes, it is necessary to use biochemical studies in the training process. They are a component of the integrated control system, a set of interconnected subsystems of pedagogical, biomedical, biomechanical, biochemical and psychological control, united by a common goal of an objective assessment of an athlete's preparedness for the proposed loads at different stages of preparation.

The purpose of biochemical control in sports is to optimize the training and competition activity of athletes based on the objective assessment of their bodies' adaptive processes during muscle activity and subsequent rest [1]. This goal is achieved by solving the three main tasks of biochemical control, presented below [12, 13].

1. Health assessment with the following selection and admission to training and competitions. Specific tasks are defined as early diagnosis of metabolic disorders and assessment of nutrition adequacy during systematic physical loads.

2. The study of a body's metabolic reaction to physical activity, which is necessary for solving specific tasks of determining the level of general and special training status of an athlete; monitoring the course of recovery processes in a body after training and competition loads; identifying the effectiveness of special tools aimed at improving efficiency and accelerating recovery processes (special nutrition, pharmacological agents, physiotherapeutic procedures, etc.).

3. Detection of doping substances in an athlete's body in a competition environment.

Biochemical studies in sports are obviously carried out in combination with physical activity, since at rest the adaptive parameters of a trained athlete are within normal limits and do not differ from the same indicators of a healthy person. It should be noted that during research, the samples are taken before the test load, then in the dynamics of physical exertion, or immediately after it, as well as in different periods of recovery $[9,10]$.

Organization of biochemical monitoring involves the simultaneous use of its several forms at different periods of training: immediate examinations and ongoing examinations; complex stage examinations; in-depth complex examinations; competition activity examinations.

\section{RESEARCH METHODOLOGY}

Speed skating is a cyclic kind for which the study of blood biochemical parameters during long-term and short-term work 
is important. It is necessary to select such differentiated methods of sports training that provide an increase in sports results without depleting of the skaters organisms [15].

The purpose of this research is to study the biochemical blood parameters of speedskaters within the framework of rational management of individual and group adaptation of athletes to physical exertion of different orientations at the general preparatory period of the training process.

The study involved two age groups of speedskaters. "Male" category includes sprinters (16 persons) and allrounders (15 persons) with the sports titles of master of sports and international master of sports. These skaters are included in the regional lists of Russian national teams and participate in Russian and international tournaments. In addition, the study involved the athletes of "youth" category, having the first sports rank and the rank of candidate for master of sports, in the amount of 29 persons.

Various biochemical blood parameters were used in the study, such as determination of hormones in serum by standardized methods at the general preparatory stage of a one-year macrocycle. These results are also planned to be used to determine the indicators' dynamics, the subsequent identification of their relationship with sports and technical results achieved during the winter competition season.

It should be noted that the study participants provided their personal informed voluntary consent for biomaterial (venous blood) sampling with the subsequent use of the results for scientific research. Mathematical processing of the research data was carried out using computer programs: "Microsoft Excel 2010", "Statistica 8.0".

Note that the youthful period is extremely important for the formation of adaptation to the increasing load in the future. At the same time, highly qualified athletes at different stages of training should also correctly approach the increase in load, in order to avoid overtraining. It is proved that there are different stages in achieving sporting results, replacing each other. Therefore, the period of bookmarking functionality is so significant.

\section{RESULTS}

Preparatory period is the time of fundamental training. In speed skating, it is divided into two major stages: general preparatory (basic) and special preparatory stages. General preparatory stage is characterized by an increase in the level of an athlete's physical fitness, improvement of physical qualities that underlie high sports achievements in a chosen sport, and the study of new motor actions. The duration of this stage depends on the number of competition periods in a one-year cycle and averages $6-8$ weeks $[2,3]$. It was at this stage that venous blood sampling from the speedskaters of various qualifications of the stated age groups in specialized institutions was organised within the study framework.

It is worth noting that a body's choice of adaptation strategies is evidenced by a change in the level of metabolites: glucose, lactate, pyruvate, fatty acids, glycerol, urea, and so on. Biochemical transformations in the blood are mainly a reflection of the processes occurring in the working muscles and in the internal organs of athletes. They depend on the nature of the work and allow assessing the involvement degree of various biochemical processes in muscles' energy supply [6]. All the obtained data on blood biochemistry are presented in tables 1,2 and 3 .

TABLE I. SOME BIOCHEMICAL INDICATORS OF BLOOD SERUM OF SPEEDSKATERS BELONGING TO "YOUTH" CATEGORY, AFTER PHYSICAL EXERTION AT THE GENERAL PREPARATORY STAGE $(\mathrm{N}=29)$

\begin{tabular}{|l|c|c|}
\hline \multicolumn{1}{|c|}{ Indicators } & $\begin{array}{c}\text { Reference } \\
\text { values }\end{array}$ & $\begin{array}{c}\text { General preparatory } \\
\text { stage, } \mathbf{X}_{\text {average }} \mathbf{\pm m}\end{array}$ \\
\hline Glucose $(\mathrm{mmol} / \mathrm{l})$ & $3,9-6,4$ & $5,37 \pm 0,473$ \\
\hline Creatinine $(\mu \mathrm{mol} / \mathrm{l})$ & $27-88$ & $86,5 \pm 7,260$ \\
\hline Urea $(\mathrm{mmol} / \mathrm{l})$ & $1,7-8,3$ & $4,58 \pm 0,684$ \\
\hline Bilirubin $(\mu \mathrm{mol} / \mathrm{l})$ & $0-20,5$ & $20,12 \pm 5,018$ \\
\hline Total protein $(\mathrm{g} / \mathrm{l})$ & $64-83$ & $75,85 \pm 3,758$ \\
\hline Lactic acid $(\mathrm{mmol} / \mathrm{l})$ & $0,5-2,2$ & $4,25 \pm 0,147$ \\
\hline $\begin{array}{l}\text { Thyroid-stimulating hormone } \\
(\mathrm{mU} / \mathrm{l})\end{array}$ & $0,23-3,4$ & $1,46 \pm 0,593$ \\
\hline Testosterone $(\mathrm{nmol} / \mathrm{l})$ & $3,61-37,67$ & $16,43 \pm 1,471$ \\
\hline Cortisol $(\mathrm{nmol} / \mathrm{l})$ & $83-580$ & $389,84 \pm 71,758$ \\
\hline
\end{tabular}

TABLE II. SOME BIOCHEMICAL INDICATORS OF BLOOD SERUM OF SPEEDSKATERS BELONGING TO “MEN" CATEGORY, AFTER PHYSICAL EXERTION AT THE GENERAL PREPARATORY STAGE $(\mathrm{N}=31)$

\begin{tabular}{|l|c|c|c|}
\hline \multirow{2}{*}{ Indicators } & \multirow{2}{*}{$\begin{array}{c}\text { Reference } \\
\text { values }\end{array}$} & \multicolumn{2}{|c|}{$\begin{array}{c}\text { General preparatory stage, } \\
\mathbf{X}_{\text {average }} \pm \mathbf{m}\end{array}$} \\
\cline { 3 - 4 } & & $\begin{array}{c}\text { Sprinters } \\
(\boldsymbol{n}=\mathbf{1 6})\end{array}$ & $\begin{array}{c}\text { All-rounders } \\
(\boldsymbol{n}=\mathbf{1 5})\end{array}$ \\
\hline Glucose $(\mathrm{mmol} / \mathrm{l})$ & $3,9-6,4$ & $5,67 \pm 1,666$ & $5,72 \pm 0,319$ \\
\hline Creatinine $(\mu \mathrm{mol} / \mathrm{l})$ & $53-97$ & $93,37 \pm 7,162$ & $96,7 \pm 3,737$ \\
\hline Urea $(\mathrm{mmol} / \mathrm{l})$ & $1,7-8,3$ & $6,87 \pm 0,972$ & $5,33 \pm 0,813$ \\
\hline Bilirubin $(\mu \mathrm{mol} / \mathrm{l})$ & $0-20,5$ & $17,87 \pm 2,380$ & $13,37 \pm 3,296$ \\
\hline Total protein $(\mathrm{g} / \mathrm{l})$ & $64-83$ & $77 \pm 1,852$ & $78,39 \pm 4,188$ \\
\hline Lactic acid $(\mathrm{mmol} / \mathrm{l})$ & $0,5-2,2$ & $4,87 \pm 0,474$ & $4,16 \pm 0,474$ \\
\hline
\end{tabular}

At the beginning of physical exertion, and sometimes even before it, the glucose concentration in blood serum increases, which happens due to an increase in liver glycogen mobilization rate. Thus, hyperglycaemia in blood serum of up to $8-9 \mathrm{mmol} / \mathrm{l}$ can be found in case of high-intensity loads, accompanied by high emotional excitement, which is not typical for the general preparatory stage [1].

Based on the data presented in Table 1, it can be seen that the average glucose in blood serum of "youth" category at the general preparatory stage is $5,37 \mathrm{mmol} / 1$. For male sprinters, this indicator, presented in Table 2, is $5,67 \mathrm{mmol} / \mathrm{l}$. In a group of all-rounders of 20-26 years, glucose level in serum was determined as an average value of $5,72 \mathrm{mmol} / \mathrm{l}$. All the results obtained in the subgroups correspond to the norm.

When comparing the indicators of young men with male sprinters, it should be noted that the glucose level in blood serum of the former is lower by $5,58 \%$, as well as when comparing with all-rounders, where the difference is $6,51 \%$. At the same time, the glucose level in blood serum of allrounders is $0,87 \%$ higher in relation to sprinters.

The consequence of changes in protein metabolism is an increase in protein concentration in plasma, the accumulation of free amino acids and ammonia in blood, as well as of the 
rapidly diffuses into blood, the lactate level in blood reflects the rate of its synthesis in muscles. The level of lactic acid in blood at rest (1-2 $\mathrm{mmol} / \mathrm{l})$ and when performing moderate power work is small (2-4 mmol/l). While in intensive work at the level of exhaustion it can reach $15-20 \mathrm{mmol} / \mathrm{l}$ or more [7, 8, 14].

An increase in the level of lactic acid in blood leads to a significant change in active medium reaction towards acid direction due to an increase in hydrogen ions concentration. Some hydrogen ions are bound by blood buffer systems (bicarbonate and haemoglobin). When the capacity of the buffer systems is exhausted, blood acidity increases, and uncompensated acidosis develops. The $\mathrm{pH}$ value can change from 7,4 at rest to 7,0-6,9 at extreme physical exertion $[4,5]$.

In accordance with the table data, the average indicator of lactic acid level in blood of the group of young men after physical exertion at the general preparatory stage corresponds to the indicators of intensive work.

It should be noted that during physical work speedskaters may experience an increase in levels of catecholamines (adrenaline and norepinephrine), cortisol, growth hormone (STH), thyroxine and other hormones in blood serum. The degree of these changes also depends on the nature of physical exertion, an athlete's fitness and specific working conditions [11].

The levels of thyroid stimulating hormone (TSH), testosterone and cortisol in blood serum of young men, sprinters and all-rounders at the general preparatory stage is presented in the Table 3.

young men at the general preparatory stage is $5,58 \mathrm{mmol} / 1$. As for adult sprinters, this parameter is $6,87 \mathrm{mmol} / \mathrm{l}$. The level of urea in blood serum of all-rounders is at the level of 5,33 $\mathrm{vmol} / \mathrm{l}$.

The average level of total bilirubin in blood serum of the group of young men at the general preparatory stage is 20,12 $\mu \mathrm{mol} / 1$. As for adult sprinters, this parameter is $17,87 \mu \mathrm{mol} / \mathrm{l}$. The level of total bilirubin in blood serum of all-rounders is at the level of $13,37 \mu \mathrm{mol} / 1$. It is worth noting that the results obtained fall within the boundaries of reference values. However, when comparing the results of the total bilirubin level in blood serum of young men with those of sprinters and all-rounders of the older age category at the general preparatory stage, it can be seen that the indicators of young men are lower by $11,18 \%$ and $33,54 \%$, respectively. The level of total bilirubin in blood serum of all-rounders is significantly lower than that of sprinters by $33,65 \%$.

When considering the table values characterizing total protein, it can be noted that the average level of this indicator in blood serum of young men at the general preparatory stage is $75,85 \mathrm{~g} / \mathrm{l}$, which is $1,51 \%$ lower than that of male sprinters, equal to $77 \mathrm{~g} / \mathrm{l}$, and $3,34 \%$ lower than that of all-rounders. In turn, the level of total protein in blood serum of all-rounders is 78,39 g/l. Moreover, all the results obtained are within the normal range. The level of total protein in blood serum of adult sprinters is lower than that of all-rounders by $1,77 \%$.

As a rule, during physical exertion the concentration of lactic acid (lactate) in blood increases. Lactate is formed in the muscles when anaerobic glycolysis is activated. Since it
TABLE III. SOME BIOCHEMICAL INDICATORS (HORMONES) OF BLOOD SERUM OF SPEEDSKATERS BELONGING TO “MEN" CATEGORY, AFTER PHYSICAL EXERTION AT THE GENERAL PREPARATORY STAGE $(\mathrm{N}=31)$

\begin{tabular}{|l|c|c|c|}
\hline \multirow{2}{*}{ Indicators } & \multirow{2}{*}{$\begin{array}{c}\text { Reference } \\
\text { values }\end{array}$} & \multicolumn{2}{|c|}{$\begin{array}{c}\text { General preparatory stage, } \\
\mathbf{X}_{\text {average }}^{ \pm \mathbf{m}}\end{array}$} \\
\cline { 3 - 4 } & & $\begin{array}{c}\text { Sprinters } \\
(\boldsymbol{n}=\mathbf{1 6})\end{array}$ & $\begin{array}{c}\text { All-rounders } \\
(\boldsymbol{n}=\mathbf{1 5})\end{array}$ \\
\hline $\begin{array}{l}\text { Thyroid-stimulating } \\
\text { hormone (mU/l) }\end{array}$ & $0,23-3,4$ & $2,14 \pm 0,597$ & $1,86 \pm 0,453$ \\
\hline $\begin{array}{l}\text { Testosterone } \\
\text { (nmol/1) }\end{array}$ & $12,1-38,3$ & $18,56 \pm 2,801$ & $22,04 \pm 3,389$ \\
\hline Cortisol (nmol/1) & $150-660$ & $588,40 \pm 34,872$ & $618,08 \pm 115,678$ \\
\hline
\end{tabular}

When analysing these data, it can be seen that the average TSH level in blood serum of young men at the general preparatory stage is $1,46 \mathrm{mU} / \mathrm{l}$. For sprinters, this indicator is 2,14 mU/l. In turn, the TSH level in blood serum of allrounders is $1,86 \mathrm{mU} / \mathrm{l}$. The results obtained are within the normal range.

When comparing the levels of TSH in blood serum of young men with that of sprinters at the general preparatory stage, it can be seen that the values of young men are lower by $46,57 \%$. In case of comparing the indicators of young men with adult male all-rounders, the indicators also turn out to be lower, yet by $27,39 \%$. The level of TSH in blood serum of sprinters is higher than that of all-rounders by $15,05 \%$. 


\section{References}

serum at the general preparatory stage in the study groups are within the established normal limits. The average level of the testosterone in blood serum of the group of young men at the general preparatory stage is $16,43 \mathrm{nmol} / \mathrm{l}$. As for adult sprinters, this parameter is $18,56 \mathrm{nmol} / \mathrm{l}$. The level of testosterone in blood serum of all-rounders is at the level of $22,04 \mathrm{nmol} / \mathrm{l}$. When comparing the testosterone level in blood serum of young men with that of sprinters and all-rounders at the general preparatory stage, it can be seen that for young men the indicators are lower by $12,75 \%$ and $34,14 \%$, respectively. The level of testosterone in blood serum of sprinters is lower than that of all-rounders by $15,78 \%$.

The level of cortisol in blood serum at the general preparatory stage of all the study groups is within the established limits of the norm. The average level of cortisol in blood serum of the group of young men at the general preparatory stage is $389,84 \mathrm{nmol} / 1$. As for adult sprinters, this parameter is $588,40 \mathrm{nmol} / \mathrm{l}$. The level of cortisol in blood serum of all-rounders is at the level of $618,08 \mathrm{nmol} / \mathrm{l}$. When comparing the indicators of cortisol level in blood serum of young men with those of adult male sprinters and all-rounders at the general preparatory stage, it can be seen that for young men the indicators are lower by $50,3 \%$ and $58,54 \%$, respectively. The level of cortisol in blood serum of sprinters is lower than that of all-rounders by $4,80 \%[7,8,14]$.

\section{CONCLUSIONS}

The revealed indicators in biochemical blood analysis (glucose, creatinine, urea, total protein, lactic acid, hormones TSH, cortisol, testosterone) of young speedskaters and adult men (sprinters and all-rounders) at the preparatory stage of a one-year macrocycle correspond to the established standards. The data obtained confirm the correctness of combining the chosen levels of physical activity in the training process of speedskaters of different qualifications. It is worth noting that the results are also used as a reference point for studying dynamics in both linked and non-linked samples. Consideration of this issue is under study in case of significant volumes and high intensity of training loads of speedskaters belonging to various qualifications and specializations in a one-year cycle, at the preparation for the main competitions of the season.

As the study showed, with regular year-round loads, the athlete's body improves. Adaptation to physical activity is being formed as a result of bioenergy rearrangements.

[1] Foster C., deKoning J.J., Uitslag T. Improving Performance in Speed Skating: Pacing Strategy or Exercise Capacity? Medicine and science in sports and exercise (57th Annual Meeting of the American-CollegeSports-Medicine/Inaugural World Congress on Exercise is Medicine, Baltimore), 2010, vol. 42, 5, pp. 176.

[2] Guba V.P. Modern time realities of integral features of effective performance of competition load. Theory and practice of physical culture. 2013, vol. 10, pp. 21-24.

[3] Guba V.P. Theory and methods of modern sports research : monograph, Sport, Moskva. 2016, 233

[4] Kamst R., Kuper G.H., Sierksma G. The Olympic 500-m speed skating; the inner-outer lane difference. Statistica neerlandica. 2010, vol. 64, 4, pp. 448-459.

[5] Konings M.J., Hettinga F.J. The Effect of Preceding Race Efforts on Pacing and Short-TrackSpeed Skating Performance. International journal of sports physiology and performance. 2018 , vol. 14, 8, pp. 970 976.

[6] Kruk E.D., Reijne M.M., de Laat B., Veeger D. Push-off forces in elite short-track speed skating. Sport biomechanics. 2019, vol. 18, 5, pp. 527 538 .

[7] Martynenko I.V., Lvovsky E.I. Formation of some indicators of longterm adaptation at skaters of different qualification in the preparatory period of macrocycle. Scientific notes of university named after P.F. Lesgafta. 2018 vol. 5 (159), pp. 174-178.

[8] Martynenko I.V., Lvovsky E.I., Yarushin S.A. The influence of loading on the organism of speed skaters with different qualifications at the general preparatory stage of the annual macrocycle. Scientific notes of university named after P.F. Lesgafta. 2018, vol. 4 (158), pp. 210-215.

[9] Menting S.J.P., Konings M.J., Elferink-Gemser M.T., Hettinga F.J. Pacing Behavior of Elite Youth Athletes: Analyzing 1500-m ShortTrack Speed Skating. International journal of sports physiology and performance. 2019, vol. 14, 2, pp. 222-231.

[10] Muehlbauer T., Panzer S., Naundorf F. Pacing and Success for the Sprint in Ice Speed Skating. Deutsche zeitschrift fur sportmedizin. 2009, vol. 60,1 , pp. 12-16.

[11] Muehlbauer T., Schindler C. Relationship between starting and finishing position in short track speed skating races. European journal of sport science. 2011, vol. 11, 4, pp. 225-230.

[12] Muehlbauer T., Schindler C., Panzer S. Pacing and Performance in Competitive Middle-Distance Speed Skating. Research quarterly for exercise and sport. 2010, vol. 81, 1, pp. 1-6.

[13] Muehlbauer T., Schindler C., Panzer S. Pacing and Sprint Performance in Speed SkatingDuring a Competitive Season. International journal of sports physiology and performance. 2010, vol. 5, 2, pp. 165-176.

[14] Oreshkina I.N., Bykov E.V., Kolomeets O.I., Martynenko I.V. Monitoring of the training process of qualified speed skaters using the FIRSTBEAT technique., Problems of Modern Pedagogical Education. Scientific journal. 2016, 53(7), pp. 153-160.

[15] Savelsbergh G.J.P., Kamper W.G., Rabius J. A new method to learn to start in speed skating: A differencial learning approach. International journal of sport psychology. 2010, vol. 41, 4, pp. 415-427.

[16] Zinaida M. Kuznetsova, Yuriy D. Ovchinnikov. Fatigue is a biomechanical category. The Russian Journal of Physical Education and Sport. 2018, 13(1), pp. 134-138. DOI: 10/14526/01_2018_298 